\title{
Ovulation detection mechanism-a microcomputer based approach
}

\author{
Olugbenga K. Ogidan $^{1 *}$, Ayodeji J. Bamisaye ${ }^{2}$, Olawumi Adetan ${ }^{3}$ \\ ${ }^{1}$ Information Communications Unit, Ondo State University of Science and Technology (OSUSTECH), Okitipupa, Nigeria; \\ ${ }^{2}$ Department of Electrical and Electronics Engineering, Federal University of Technology, Akure, Nigeria; \\ ${ }^{3}$ Department of Electrical and Electronics Engineering, University of Ado Ekiti, Ado Ekiti, Nigeria. \\ E-mail: *gbengaogidan@yahoo.com, ayobamisaye@ieee.org, wumtay@yahoo.com
}

Received 8 June 2011; revised 2 August 2011; accepted 9 November 2011.

\begin{abstract}
This paper presents a real-time microcomputer-based logger for measuring basal body temperature (BBT). BBT is the normal resting body temperature of a healthy person immediately upon waking in the morning. The temperature for women normally rises after ovulation due to hormonal changes. The temperature is logged real-time into the computer over a period and the BBT chart produced is used to predict ovulation. There is high correlation between the approach developed by this study and other standard measuring equipments-correlation of 0.9945 with standard thermistor, and correlation of 0.9977 with standard thermocouple. This development enables privacy of use, allowing women to predict their ovulation status at a personal level.
\end{abstract}

Keywords: Basal Body Temperature (BBT); Microcomputer-Based Logger, Ovulation, Thermistor, Thermocouple and Correlation

\section{INTRODUCTION}

Infertility is the inability of a couple to obtain a clinical recognizable pregnancy after 12 months of unprotected intercourse. The alarming rate of infertility among couples calls for serious efforts and attention from any woman who is serious about getting pregnant. Most women, and sometimes their partners, would want to learn when ovulation and implantation occurs and what is the best time for intercourse to achieve pregnancy. Timing the ovulation period is a very important step towards getting pregnant. With the latest scientific improvements, several methods and tests are available for determining, with a high degree of certainty, when your ovulation occurs. These include [1,2]:

Calendar Charting/Ovulation Calculator: Using this method, a woman uses her past menstrual cycle as a guide. This is done by calculating the average number of days in her cycle, to estimate the future fertile times.

Cervical Mucus Monitoring: In this method, the cervical fluid is monitored each day. At the beginning of ovulation, the cervical fluid will go from dry or sticky to creamy like a lotion, and finally will become like egg white. Many women compare mucus at this stage to raw egg whites. A woman is most fertile during the egg white phase.

Cervical Observation: The position of a woman's cervix is used to determine ovulation. During and in the first few days after menstruation, the cervix is fairly low and firm like the tip of a nose. When the wet cervical fluid begins to show, the cervix begins to move up, becomes more soft, wet and open. During ovulation, the cervix is at its highest and most open. After ovulation, the cervix returns to its low, firm and closed position.

Lower Abdominal Discomfort: About one-fifth of women actually feel ovulatory activity, which can range from mild achiness to twinges of pain. The condition, called mittelschmerz, may last a few minutes to a few hours [3].

Basal Body Temperature (BBT): The basal body temperature graph is probably the most widely used aid in the identification of the day of ovulation [4,5] Following ovulation, a woman's temperature rises by 0.4 to 1.0 degrees and remains up till next menstruation period. This temperature-spike indicates ovulation has occurred. This is because releasing an egg stimulates the production of the hormone progesterone, which raises the body temperature $[2,6]$. The body might not feel this shift in temperature, however with a more sensitive device, it could be easily detected. This study attempts to develop a user-friendly, microprocessor-based basal body temperature (BBT) logger capable of detecting and recording the slightest shift in basal body temperature. This paper is arranged as follows: Section 2 describes the method, design and theory adopted, Section 3 shows 
the performance testing and analysis, while the result and conclusion drawn are presented in Sections 4 and 5 respectively.

\section{MATERIALS AND METHODS}

A simple but sensitive temperature sensory device (called data-logger) was designed to measure basal body temperature (BBT). The device is portable and battery powered. This device contains a temperature sensor-negative temperature coefficient (NTC) thermistor, which transduces the temperature into electronic analog signal. The analog signal is then passed into an analog to digital converter (ADC). The converted signal is then received and transmitted (using a transceiver) to the microcomputer through the parallel port [7]. In the laboratory setting, a personal computer is used. The arrangement is illustrated in Figure 1. A computer program in Visual Basic 6.0 was then written to address the parallel port and to log the data into a user-friendly interface where the temperature is both interpreted and analyzed. The circuit diagram is shown in Figure 2, while Figure 3 presents how the device is interfaced with a personal computer.

\section{PERFORMANCE TESTING AND ANALYSIS}

After, the individual circuit stages and the software were tested; the assembly was then tested connecting to a human being (a lady of $21 \mathrm{yr}$ ). The temperature was logged into the computer over a period of time. This was done also with a mercury thermometer and the readings were found to be almost the same with a difference of

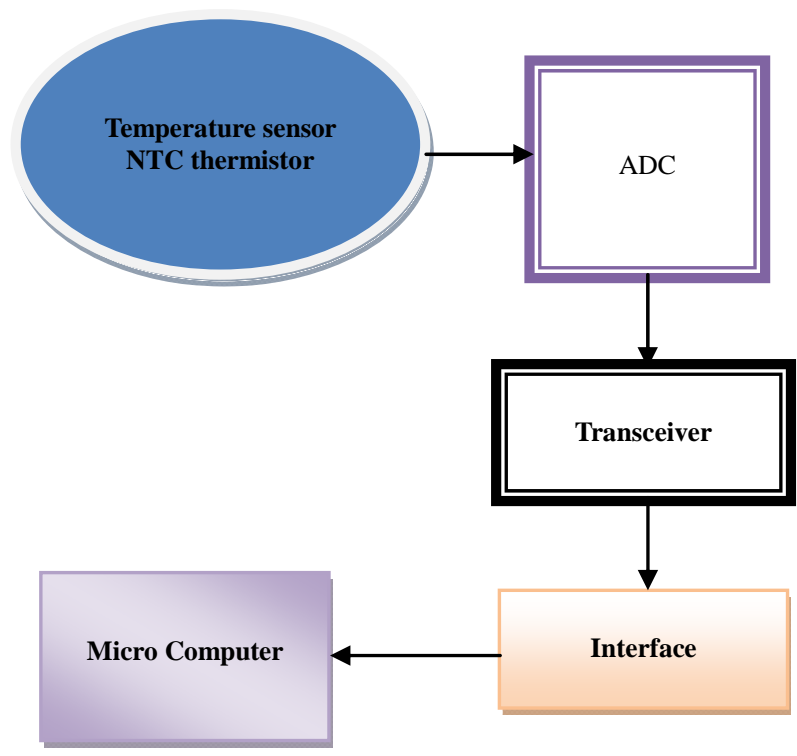

Figure 1. Block diagram of a Basal Body Temperature (BBT) Microcomputer Logger. Let Figure 2 be labelled as Circuit diagram showing NTC thermistor with a PC parallel port.

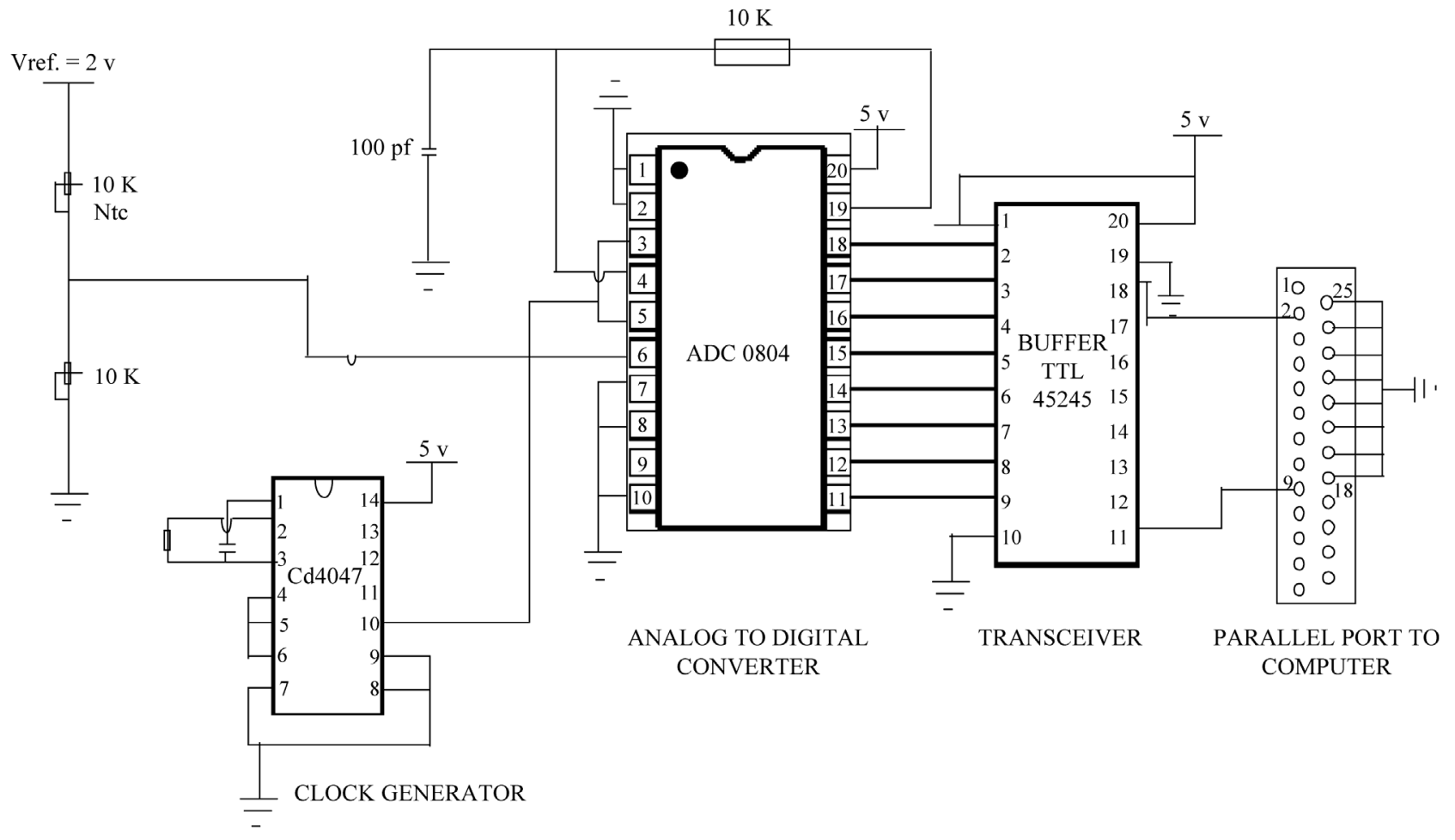

Circuit Diagram showing NTC Termistor interfaced with a PC parallel potr

Figure 2. Circuit diagram. 


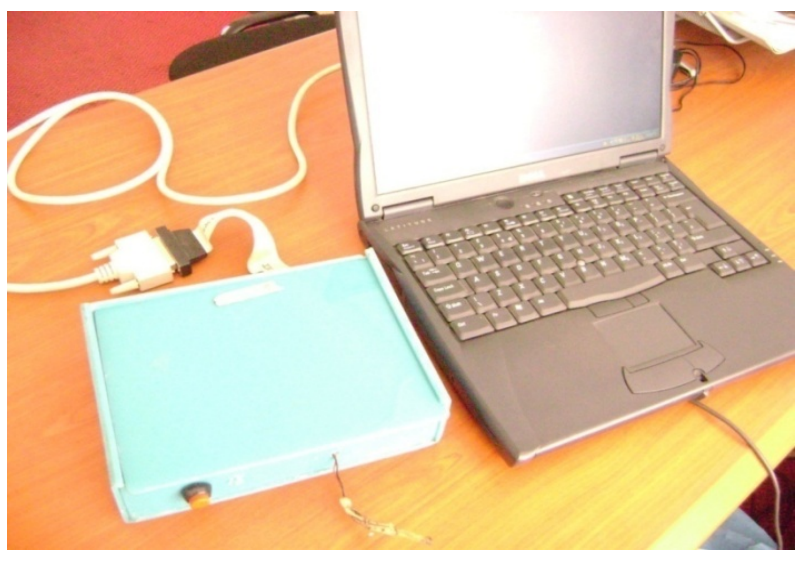

Figure 3. Diagram of a basal body temperature (BBT) logger interfaced with a personal computer.

$0.02^{\circ} \mathrm{C}$.

The software was tested and found to be able to:

- Measure and log human temperature into the computer real-time;

- Start and stop logging automatically and raise an audible alarm or give a visual message when the reading is beyond a pre-set (threshold) value.

- Give the temperature reading as well as details of the date, time (minute, second)

It must be noted however that the temperature sensor would have to be attached to the body under examina- tion in order to take the reading for a period of time.

In this paper, the temperature measurement device was calibrated against two known standard digital thermometers using thermistor and thermocouple as sensors. The correlation with thermistor and thermocouple was 0.9945 and 0.9977 respectively. Therefore, calibration can be defined as the process of determining the characteristic relationship between the values of the physical quantity applied to an instrument and the corresponding positions of the display [6].

Table 1 shows the table of data recorded every 120 seconds.

\section{RESULTS AND DISCUSSION}

The basal body temperature (BBT) measured was logged into a user-friendly interface that facilitates the viewing, digital recording and graphical representation of the measured temperature was presented in Figure 4, any change (rise or low) in temperature for a specific period of time can easily be detected and analyzed. The developed logger was used (at room temperature) to measure atmospheric temperature alongside standard temperature sensors (thermistor and thermocouple) for about one hour(between 8 am and 9 am). The correlation with thermistor was 0.9945 and 0.9977 with thermocouple. The results tend to unity thus showing a high degree of measurement reliability. Figure 5 shows the graph of the

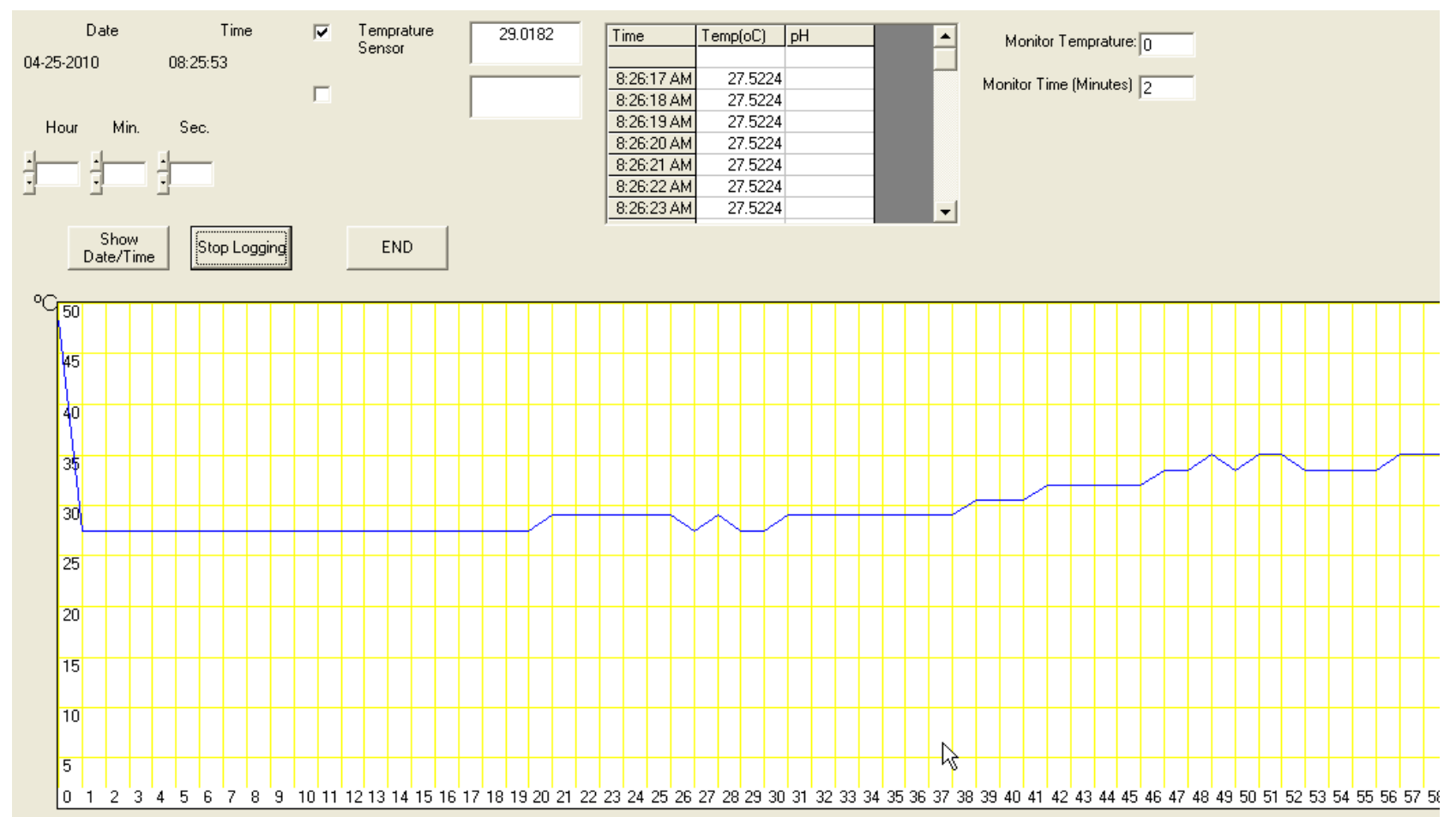

Figure 4. User-friendly interface showing graphical representation of temperature measured by the logger. 
Table 1. Data recorded every 120 seconds from 8 am to 9 am using standard thermistor, standard thermocouple and Developed data logger.

\begin{tabular}{|c|c|c|c|}
\hline $\begin{array}{l}\text { Time (secs) } \\
8 \text { am - } 9 \text { am }\end{array}$ & Develop & Standard TH & Standard THC \\
\hline 120 & 25.62 & 25.69 & 25.67 \\
\hline 240 & 27.54 & 27.58 & 27.55 \\
\hline 360 & 27.60 & 27.64 & 27.55 \\
\hline 480 & 27.68 & 27.58 & 27.68 \\
\hline 600 & 27.72 & 27.60 & 27.55 \\
\hline 720 & 27.72 & 27.60 & 27.55 \\
\hline 840 & 28.71 & 28.60 & 28.67 \\
\hline 960 & 28.50 & 28.55 & 28.50 \\
\hline 1080 & 28.44 & 28.55 & 28.50 \\
\hline 1200 & 28.50 & 28.55 & 28.50 \\
\hline 1320 & 28.52 & 28.55 & 28.50 \\
\hline 1440 & 28.66 & 28.63 & 28.67 \\
\hline 1560 & 28.88 & 28.71 & 28.84 \\
\hline 1680 & 28.60 & 28.63 & 28.66 \\
\hline 1800 & 28.82 & 28.71 & 28.84 \\
\hline 1920 & 28.66 & 28.63 & 28.67 \\
\hline 2040 & 28.66 & 28.63 & 28.67 \\
\hline 2160 & 28.60 & 28.63 & 28.66 \\
\hline 2280 & 28.84 & 28.71 & 28.84 \\
\hline 2400 & 28.66 & 28.63 & 28.67 \\
\hline 2520 & 28.62 & 28.63 & 28.66 \\
\hline 2640 & 28.86 & 28.71 & 28.84 \\
\hline 2760 & 28.44 & 28.55 & 28.50 \\
\hline 2880 & 28.64 & 28.62 & 28.65 \\
\hline 3000 & 28.46 & 28.55 & 28.50 \\
\hline 3120 & 28.66 & 28.63 & 28.67 \\
\hline 3240 & 28.64 & 28.62 & 28.65 \\
\hline 3360 & 28.66 & 28.63 & 28.66 \\
\hline 3480 & 28.64 & 28.62 & 28.65 \\
\hline 3600 & 28.66 & 28.63 & 28.67 \\
\hline \multicolumn{2}{|c|}{$\begin{array}{l}\text { Correlation with develop } \\
\text { thermometer }\end{array}$} & 0.9945748 & 0.997785 \\
\hline
\end{tabular}

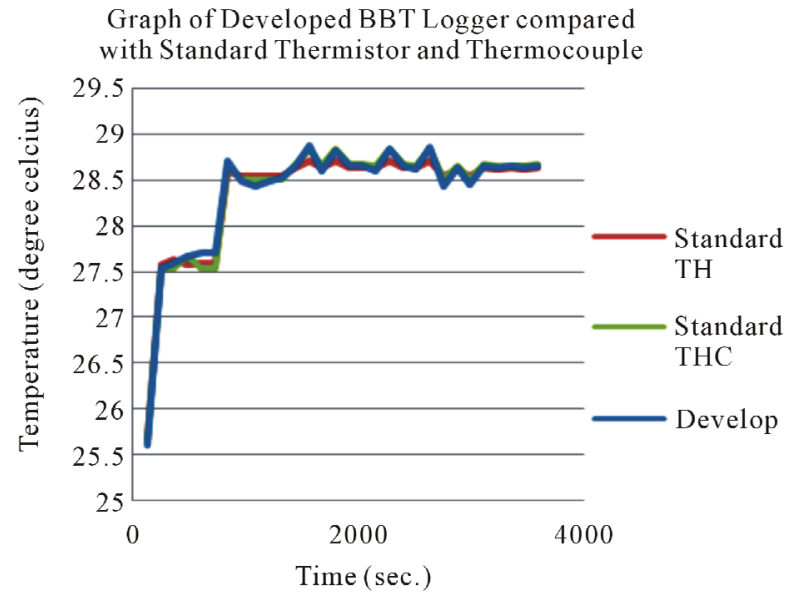

Figure 5. Graph of developed BBT logger compared with standard thermistor and thermocouple when used to measure atmospheric temperature.

comparison.

\section{CONCLUSION}

This study has developed a Basal Body Temperature (BBT) logging system, which makes fertility charting very easy. The system has been calibrated and is being put to clinical use. The developed logger compares favourably with standard thermistor with a correlation of 0.9945, and with standard thermocouple with a correlation of 0.9977. This device has many advantages including enabling privacy, provides non-intrusive method of ovulation detection; provides data easily to physicians which could be interpreted for diagnosis and treatment of their patients; and has a good potential for telemedicine.

\section{ACKNOLEDGEMENTS}

The researchers acknowledge Prof. M.O Kolawole and Dr V.S.A Adeloye for their immense assistance and contribution and also The Federal University of Technology, Akure, Nigeria.

\section{REFERENCES}

[1] Feminist Women's Health Centerv (FWHC) (2004), accessed 23 December 2009. http://www.fwhc.org/

[2] WHO, (2004) Medical eligibility criteria for contraceptive use: fertility awareness-based methods. World Health Organization, Retrieved 2010.

[3] Ross, M.H. and Pawlina, W. (2006) Histology: A text and Atlas. Lippincott Williams \& Wilkins, Philadelphia.

[4] Moghissi, K.S. (1976) Accuracy of basal body temperature for fertility detection. Fertil Steril, 27, 1415-1421.

[5] Weschler, T. (2002) Taking charge of your fertility. Harper Collins, New York.

[6] Ogidan, O.K. (2010) Design and construction of real-time logging system. Master's Thesis. Department of Electrical and Electronic Engineering, The federal University of 
Technology, Akure, Nigeria.

[7] Axelson, (2000) Parallel port complete. Lakeview Re- search Publisher, Madison, 10-30. 